УДК 1

DOI $10.21661 / \mathrm{r}-551605$

\title{
П.Е. Хайлов
}

\section{ПСИХОЛОГИЧЕСКИЕ УСЛОВИЯ ЭФФЕКТИВНОЙ РЕКЛАМЫ}

Аннотация: статья посвящена анализу рекламь и ее воздействию на потребительское поведение и выбор. Дается обоснование подобных процессов с точки зрения психологии. Автором также рассматриваются психологические методы и критерии оценки эффективности рекламы. Приводится и анализируется пример с конкретным рекламным кейсом. В работе выявляется несколько ключевых условий эффективности рекламы.

Ключевые слова: реклама, психология, влияние, покупательское поведение, потребление, методы воздействия, эффективность рекламы, маркетинг.

\section{P.E. Khailov}

\section{PSYCHOLOGICAL CONDITIONS FOR EFFECTIVE ADVERTISING}

Abstract: the article is devoted to the analysis of advertising and its impact on consumer behavior and choices. A justification of such processes from a psychological point of view is given. Psychological methods and criteria for evaluating the effectiveness of advertising are also considered. An example of a specific advertising case is presented and analyzed. Several key conditions for effective advertising are identified.

Keywords: advertising, psychology, impact, consumer behavior, consumption, methods of influence, advertising effectiveness, marketing.

Современную жизнь человека трудно представить без рекламы. Реклама окружает нас буквально повсюду: на улицах города, в магазинах, при просмотре телевизионных передач, при прослушивании музыки на радио, при использовании сети Интернет. Каналы и методы воздействия рекламы на человека могут быть самыми разнообразными. Однако каким бы ни было рекламное сообщение по форме и содержанию, по каналу распространению и широте охвата, основной целью его всегда будет являться воздействие на психику человека с тем, чтобы 
сформировать у него положительное отношение к рекламируемому объекту и повлиять на его покупательское решение в пользу данного объекта.

На сегодняшний день в условиях революционного развития конкуренции даже самые крупные и зарекомендовавшие себя на рынке многолетним трудом компании вынуждены бороться за потребителя. Постоянный рост дифференциации предложения способствовали тому, что потребитель стал более требовательным и взыскательным. Но на потребительское поведение влияет не только ситуация на рынке. Только компании, в центре внимания которых находится потребитель, способны не просто производить товары, но и психологически воздействовать на покупателей по средствам эффективной рекламы. Поэтому пристальное изучение психологических условий эффективной рекламы, особенностей психических процессов потребителя при воздействии на него рекламного сообщения позволит специалистам в области рекламы и маркетинга на практике определить для себя оптимальный инструментарий для создания эффективной рекламы.

Реклама - это информация, направленная на определенное лицо или аудиторию и воздействующее на него в целях продвижения рекламного объекта. При этом, реклама является односторонней коммуникацией, т. е. информация передается от рекламодателя к потребителю, но не обратно [1].

Современная реклама ставит перед собой различные цели. К основным целям можно отнести:

1) информирование потребителя о товарах, услугах, фирмах и т. д.;

2) представление потребителю выгоды от приобретения рекламируемого товара либо услуги;

3) создание и поддержание положительного имиджа фирмы, торговой марки, продавца и т. д.;

4) стимулирование сбыта;

5) напоминание целевой аудитории о товарах, услуге, фирме. 
Также можно выделить несколько функций рекламы, так как использование ее инструментов всегда имеет под собой различные причины. Разделяют следующие функции рекламы:

1. Коммуникативная функция рекламы выражается в том, что реклама является средством общения, передачи информации от рекламодателя к покупателю. Существует формула рекламной коммуникации, предложенная Г.Д. Лассвелом: «Кто говорит, что говорит, кому говорит, по какому каналу, с какой целью» [2].

2. Экономическая функция рекламы заключается в том, что реклама, будучи экономическим явлением, воздействует на субъекты и участников экономических отношений. Реклама стимулирует спрос и сбыт, оказывая влияние на оборот товаров и услуг. Также реклама способствует развитию рыночной конкуренции. Реклама позволяет расширять производство товаров и услуг, благодаря чему обеспечивается рост занятости населения. И еще одной экономической подфункцией рекламы является то, что она финансирует многие СМИ, благодаря которым рекламодатель имеет возможность выхода на целевую аудиторию.

3. Социальная функция рекламы или социальная роль выражается во влиянии рекламы на общество. Она работает на повышение жизненного уровня людей, распространяет среди масс культурные, экономические, материальные и нематериальные рыночные возможности. Реклама способствует формированию культурного, правового, экономического менталитета населения. Также благодаря рекламе создаются различные общественные организации, движения, СМИ [3].

4. Идеологическая функция рекламы, по мнению американского социолога Джанкарло Бузи, заключается в том, что любое рекламное сообщение старается подчинить мнение людей и их поведение под определенную идеологию, унифицировать определенные стороны жизнедеятельности потребителя [4].

5. Имиджевая функция рекламы заключается в создании и поддержании благоприятного или любого другого имиджа компании, торговой марки, человека. 
Впервые исследования рекламы с точки зрения психологии стали проводиться на рубеже XIX-XX вв. с появлением новых рекламных технологий возникла необходимость большего изучения психологического воздействия на человека. Реклама представляет собой социально-психологическое явление. Информация, закодированная в ней, способна активировать даже самые скрытые аспекты человеческой психики. Психологическое воздействие рекламы проявляется на этапах обработки рекламных сообщений - эмоциях, мыслях, выбора решений, от которых в итоге зависит потребительское поведение. Таким образом рекламный процесс неразрывно связан с с психологическими процессами обработки информации: ощущениями, вниманием, памятью, восприятием и т. д. В то же время, в процессе переработки рекламной информации задействовано отношение человека к рекламному сообщению на эмоциональном уровне, а также чувства понимания и принятия или отторжения содержания рекламной информации [5].

Воздействие рекламы на психику человека происходит в основном за счет воздействия на такие виды ощущений как слуховые, зрительные, вкусовые, осязательные, обонятельные и другие виды. Для того чтобы привлечь внимания к рекламируемому товару производителю рекламы необходимо создать такие ощущения от рекламы, которые покажутся потребителю новыми. Например, приятный запах парфюмерии (реклама салона парфюма, направленная на обоняние человека) будет отличаться от других запахов в торговом центре и восприниматься как нечто новое, привлекая потребителя).

Визуальный язык является универсальным и более легок для восприятия, чем, например, вербальный. Использование иллюстраций в рекламе позволяет потребителю быстрее считывать информацию, чем при прочтении заголовков и текстов. Для эффективного воздействия на потребителя необходимо действовать при создании рекламы в соответствии с требованиями, предъявляемыми к визуальным рекламным образам. Среди этих требований: четкость и ясность, цвет, контрастность объекта, соблюдение баланса центра и силы, пропорции, размер, сходство, размещение объекта рекламы на нейтральном фоне. 
Цвет - наиболее эффективный способ привлечения внимания потребителя и влияния на его эмоциональное состояние. Например: желто-красные тона создают чувство взволнованности, возбуждения; синие, серые цветовые тона, напротив, действуют успокаивающе; черный или серый цвет обладает значением изысканности, культурности и как бы противостоит всей гамме «вульгарных красок» [6].

Таблица 1

Психологическое воздействие цвета в рекламе

\begin{tabular}{|l|l|}
\hline \multicolumn{1}{|c|}{ Цвет } & \multicolumn{1}{|c|}{ Психофизиологическое воздействие } \\
\hline Коричневый & Теплый, земной, статичный, тяжелый, аморфный \\
\hline Красный & Опасный, решительный, агрессивный, динамичный, быстрый, тяжелый \\
\hline Желтый & $\begin{array}{l}\text { Радостный, солнечный, сохраняется в памяти, привлекает внимание, } \\
\text { теплый, легкий, увеличивает }\end{array}$ \\
\hline Оранжевый & Жизнерадостный, импульсивный, теплый, приближает, увеличивает \\
\hline Зеленый & Неопасный, успокаивающий, здоровый, нейтральный, мягкий \\
\hline Синий & Холодный, надежный, чистый, воздушный, далекий, свежий, уменьшает \\
\hline Белый & Больничный, чистый, открытый, увеличенный, легкий \\
\hline Серый & Стальной, технический, прогрессивный, легкий \\
\hline Черный & Печальный, статичный, устойчивый, изящный, тяжелый, уменьшенный \\
\hline
\end{tabular}

Психологическое воздействие рекламы на потребителя осуществляется за счет различных методов воздействия. Раскроем основные методы.

1. Метод социально-психологической установки. Данный метод работает путем создания установок в сознании человека путем создания в рекламе такого сюжета, который напоминал бы общение с другими людьми, которые делятся своим опытом. Например: «Я уже давно избавилась от этой проблемы, покупайте такую же вещь и живите без проблем».

2. Метод прямого внушения. Сила прямого внушения во многом зависит от веры в возможности оратора. В данном методе могут использоваться суггестивные команды, приказы, множество раз повторяющиеся жесты, мимика и интонация оратора. В рекламе данный метод в основном используется на стадионах, массовых мероприятий, где находятся большие массы людей, «запрограммированные на чудо». Носит вербальный характер [7]. 
3. Метод косвенного внушения. Внушение предполагает непрямое и неаргументированное воздействие на одного человека или целевую аудиторию. Внушение происходит в скрытой, завуалированной форме и получатель информации не осознает воздействия, оказываемого на него.

4. Метод подражания. Подражание является одним из самых эффективных способов воздействия в рекламе. Реклама в данном случае изображает потребителю то, что является для него эталоном, чем-то престижным. Например, популярная актриса рекламирует помаду. В данном случае у представительниц целевой аудитории возникнет желание подражать авторитетному персонажу рекламы.

5. Метод психического заражения. Выражается в том, что многие люди на бессознательном уровне подвержены определенным психическим воздействиям, перенимая на себя чужое эмоциональное состояние. Метод особенно эффективен при воздействии на молодежь, а также на массовых мероприятиях.

6. Метод убеждения. Один из наиболее распространенных методов психологического воздействия рекламы на целевую аудиторию. По мнению психологов, убеждение, прежде всего, обращается к интеллектуальным, мыслительным способностям человека. Основан метод на том, чтобы при помощи аргументов заставить потребителя внутренне согласиться с том, в чем его убеждают, а затем создать у него новые установки, которые будут отвечать поставленным целям.

Для оценки эффективности рекламы обычно используют экономический или финансовый подход. Он представляет собой экономический результат, полученный от организации рекламной деятельности. В целом данная эффективность рассматривается между отношением валового дохода от дополнительного товарооборота в результате рекламы и затрат на нее. Оценка экономической эффективности проводится по материалам бухгалтерских отчетов и статистических данных. Проблема заключается в том, что реклама не дает мгновенного экономического результата и в то же время рост товарооборота может быть связан с другими факторами, не относящимися к рекламе (например, рост цен на рынке). В связи с эти данные об экономической эффективности не могут быть точными 
на сто процентов и имеют свою погрешность. Для оценки экономической эффективности рекламы маркетологи и специалисты по рекламе применяют различные формулы ROI или ROMI.

Рекламные приемы и воздействия лучше всего видны в рекламных роликах автомобилей, к примеру, Mersedes-Benz. Практически в каждой рекламе этого бренда есть элементы имиджа компании и их продуктов. Зачастую используется либо пейзаж природы или городских зданий (смотря какой продукт рекламируется). Присутствует низкий мужской голос и звук двигателя, что отсылает нас к целевой аудитории компании. Панорамные кадры автомобиля сделаны плавно и качественно, что внушает доверие к сборке и вызывает чувство комфорта. Актеры в таких видео всегда ухожены и могут быть в кадре с симпатичной актрисой. Эти и другие факторы (роскошный салон автомобиля, атрибуты главного героя дорогая одежда, личный бассейн, часы и т. д.) вызывали ощущение роскоши.

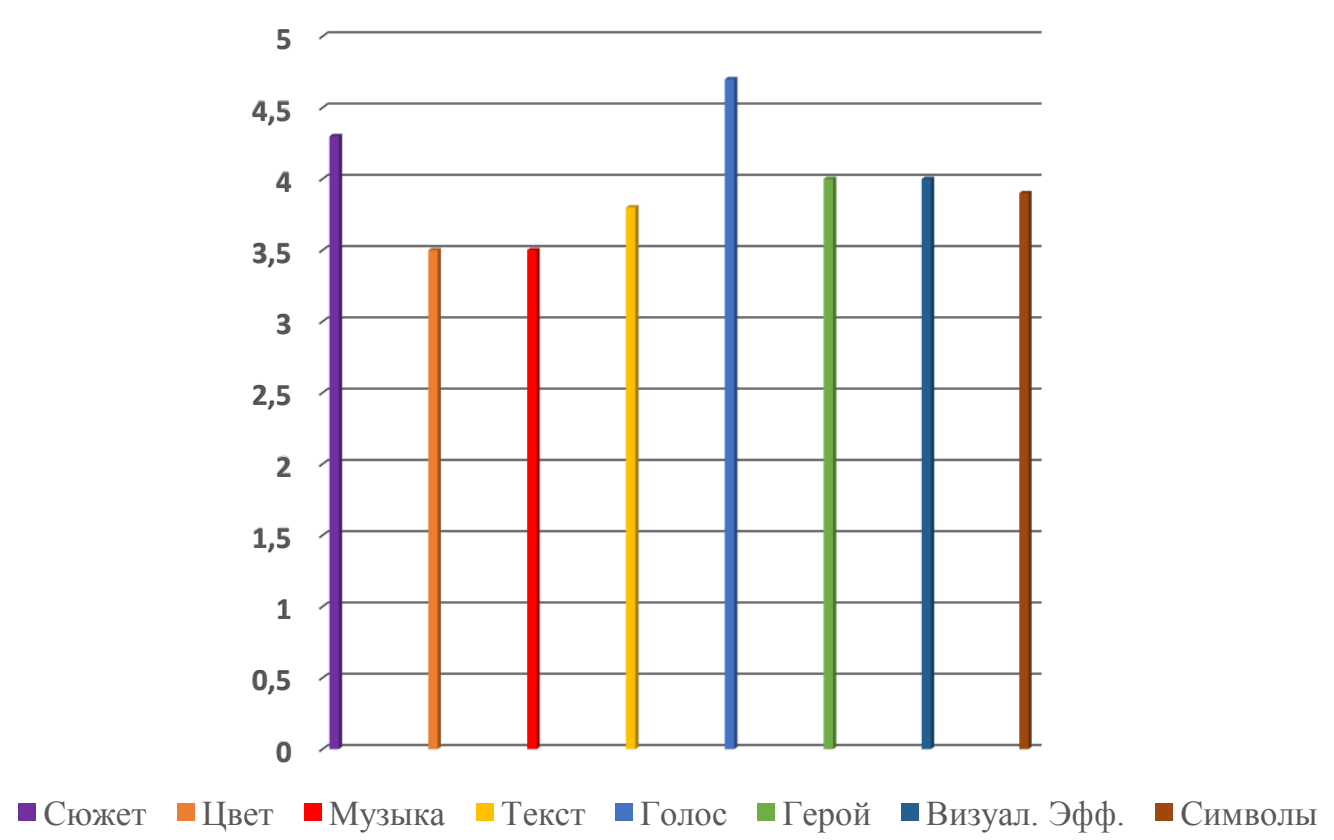

Рис. 1. Условное влияние каждого фактора в рекламном ролике

Сегодня не каждая реклама может считаться эффективной, если не созданы специальные психологические условия ее эффективности. Эффективность рекламы может зависеть от различных факторов, и оценка ее эффективности никогда не бывает абсолютно точной. Но особый интерес рекламы, как инструмента 
воздействия на человека, представляет то, какие психологические методы и приемы используются для создания эффективной рекламы.

Реклама всегда ставит перед собой целью информирование человека о товарах или услугах, привлечение его внимания и побуждение его к приобретению товара или услуги. Для решения таких целей применяется целый набор форм психологического воздействия на потребителя. Он варьируется от канала распространения рекламы.

\section{Сиисок литературы}

1. Гусева О.Ю. Психология рекламной деятельности: учебное пособие / О.Ю. Гусева. - Н. Новгород: НГЛУ им. Н.А. Добролюбова, 2006. - 10 с.

2. Николаева М.А. Основы рекламы: интегративный курс: учебно-методический комплекс / М.А. Николаева. - Екатеринбург, 2012. - 28 с.

3. Бернадская Ю.С. Основы рекламы: учебник / Ю.С. Бернадская, С.С. Марочкина, Л.Ф.Смотрова; под ред. Л.М. Дмитриевой. - М.: Наука, 2005. - 16 с.

4. Чабанюк Т.А. Теория и практика рекламы: учеб. пособие / Т.А. Чабанюк. - Комсомольск-на Амуре: ФГБОУ ВПО «КнАГТУ», 2013. - 6 с.

5. Шуванов В.И. Психология рекламы [Электронный ресурс]. - Режим доступа: https://www.litmir.me/br/?b=217845\&p=2

6. Глибенко Н.В. Психология дизайна рекламы и средств её распространения / Н.В. Глибенко, С.Н. Басова // Молодой ученый. - 2012. - №8. - С. 259-267 [Электронный ресурс]. - Режим доступа: https://moluch.ru/archive/43/5212/

7. Мусаелян Э.Р. Психологическое воздействие рекламы на человека // Транспортное дело России. - 2012. - №5 [Электронный ресурс]: https://cyberleninka.ru/article/n/psihologicheskoe-vozdeystvie-reklamy-na-cheloveka

\section{References}

1. Guseva, O. Iu. (2006). Psikhologiia reklamnoi deiatel'nosti: uchebnoe posobie., 10. N. Novgorod: NGLU im. N.A. Dobroliubova.

2. Nikolaeva, M. A. (2012). Osnovy reklamy: integrativnyi kurs: uchebnometodicheskii kompleks., 28. Ekaterinburg. 
3. Bernadskaia, Iu. S., Marochkina, S. S., \& Smotrova, L. F. (2005). Osnovy reklamy: uchebnik., 16. M.: Nauka.

4. Chabaniuk, T. A. (2013). Teoriia i praktika reklamy: ucheb. posobie., 6. Amure: FGBOU VPO "KnAGTU".

5. Shuvanov, V. I. Psikhologiia reklamy. Retrieved from https://www.litmir.me/br/?b=217845\&p=2

6. Glibenko, N. V., \& Basova, S. N. (2012). Psikhologiia dizaina reklamy i sredstv eio rasprostraneniia. Young scientist, 8, 259-267. Retrieved from https://moluch.ru/archive/43/5212/

7. Musaelian, E. R. (2012). Psikhologicheskoe vozdeistvie reklamy na cheloveka. Transport Business in Russia, 5. Retrieved from https://cyberleninka.ru/article/n/psihologicheskoe-vozdeystvie-reklamy-na-cheloveka

Хайлов Павел Евгеньевич - магистрант, ФГБОУ ВО «Российская академия народного хозяйства и государственной службы при Президенте РФ», Москва, Россия.

Khailov Pavel Evgenevich - master's degree student, FSBEI of HE "The Russian Presidential Academy of National Economy and Public Administration", Moscow, Russia. 